\title{
Deep Brain Stimulation in "On"-State Parkinson Hyperpyrexia 田
}

Figure Time course of parkinsonism hyperpyrexia syndrome and complications

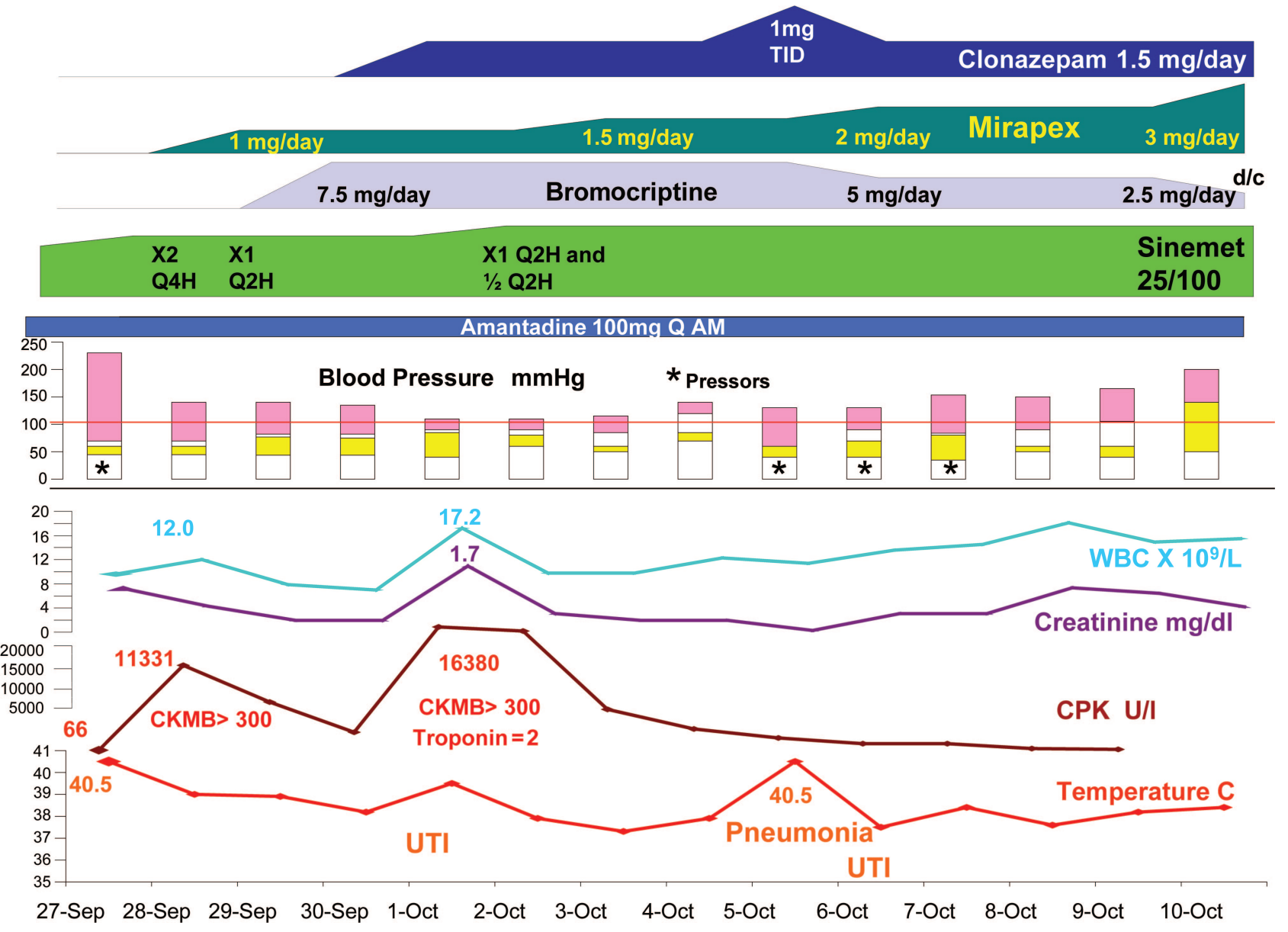

arkinsonism hyperpyrexia syndrome (PHS) is a life-threatening condition seen in Parkinson disease (PD)
characterized by high fever, muscle rigidity, elevated creatine phosphokinase (CPK), autonomic instability,
and altered consciousness. Serious complications, such as rhabdomyolysis, renal failure, disseminated intravascular coagulation, and infections, are common. ${ }^{1-3}$ Withdrawal from dopamine replacement therapy (DRT), infection, injury, surgery, dehydration, and metabolic abnormalities can provoke PHS. ${ }^{4}$ Treatment includes increasing the frequency of DRT and management of systemic complications. Mortality is $4 \%$ if treated and 16\% if untreated. ${ }^{5,6}$ Among survivors, 30\% have worsening of symptoms of parkinsonism and never return to their baseline.

Supplemental data at www.neurology.org
CASE REPORT A 52-year-old woman with a 17-year history of PD was referred for deep brain stimulation (DBS) surgery. She had bilateral tremor, rigidity, gait impairment, postural instability, motor fluctuations with dyskinesias, and wearing off symptoms of limb dystonia and freezing. Medications included carbidopa/ levodopa (CD/LD) and amantadine. The Unified Parkinson's Disease Rating Scale-motor subscore (UPDRS-III) in a challenged "on" state was 27 (video 1 on the Neurology ${ }^{\circledR}$ Web site at www.neurology.org). Off medication ( $>12$ hours) she had such severe tremor and rigidity in the waiting area that a physician passing by sent her to 
the emergency room for presumed status epilepticus, where she had a temperature of $37.8^{\circ} \mathrm{C}$, diaphoresis, tachycardia, hypertension, dehydration, leukocytosis, and a CPK of 926 U/L. She improved after IV hydration and taking her medication.

The family reported that the patient had been having 2-hour episodes every evening for 5 years of severe tremor, rigidity, and diaphoresis, and she felt warm, without clear precipitating factors. The tremor was so severe that the patient's bed was "shaking as in an earthquake," and they could not bend her stiff extremities.

One month later, the patient was admitted to the intensive care unit with a fever of $40.5^{\circ} \mathrm{C}$, tachycardia, tachypnea, and autonomic instability. During the subsequent 3 weeks, her systolic blood pressure ranged from 230 to $80 \mathrm{~mm} \mathrm{Hg}$, requiring pressure support at times. She experienced severe motor fluctuations with instant changes from marked wholebody dyskinesias to rigidity, tremor, diaphoresis, and hyperpyrexia. These extreme states sometimes coexisted in different parts of her body (video 2). She had recurrent episodes of rhabdomyolysis with maximum CPK 16,380 U/L, demand cardiac and liver ischemia, aspiration pneumonia, severe autonomic instability, urinary tract infections, and a lacunar ischemic stroke. The patient eventually responded to hourly doses of CD/LD during her waking hours, amantadine, pramipexole, bromocriptine, and intermittent doses of dantrolene and clonazepam (figure). Feeding through a gastrostomy tube (GT) was administered at night only to eliminate the possibility of recurrence of PHS due to enteric binding of LD. ${ }^{7,8}$ At one point the patient expressed a desire to stop all medical care and die. She was convinced to continue and subsequently was discharged after 29 days of hospitalization, on hourly doses of CD/LD per GT, causing constant disabling dyskinesias. The evening episodes of tremor and rigidity persisted. She remained dependent on the fulltime care of one daughter.

Bilateral subthalamic nucleus (STN) DBS implantation with microelectrode recording was performed on medication. CD/LD was administered hourly per GT intraoperatively due to the concern of triggering an episode of PHS if medication was withdrawn. The patient was dyskinetic throughout the procedure. However, intraoperative STN DBS resulted in immediate resolution of dyskinesias (video

\section{Parkinsonism Hyperpyrexia Syndrome}

- High fever, muscle rigidity, elevated CPK, autonomic instability, altered consciousness, and more serious complications

- May be provoked by several circumstances

- May respond to DBS
3), which returned when stimulation was stopped. Due to this, the dual-channel pulse generator was implanted at the same time, and was activated 5 hours later, in a monopolar mode, contact 1 negative, rate $185 \mathrm{~Hz}$, pulse width $60 \mu \mathrm{s}$, amplitude 3.0 $\mathrm{V}$ bilaterally (video 4 ).

In the 54 months since, the patient has had no more episodes of PHS or autonomic instability. The UPDRS-III score improved to $9(66 \%)$ and medications were gradually reduced by $77 \%$. She gained $13 \mathrm{~kg}$ of weight and became independent in activities of daily living. Her daughter is now employed outside the home.

DISCUSSION This patient almost died due to complications of PHS and was susceptible to a recurrent state of autonomic instability, hyperpyrexia, and rhabdomyolysis. In light of this and her severe motor fluctuations on medication, young age, and lack of cognitive impairment, STN DBS was considered. The procedure was performed on medication, despite total body dyskinesias, as it has been shown that subjects with PD may develop PHS at or after STN DBS implantation with acute medication withdrawal or reduction. ${ }^{9-11}$ Interestingly, there was immediate resolution of dyskinesias in the operating room, and with gradual withdrawal of $\mathrm{CD} / \mathrm{LD}$, once the DBS was "on," there has been no recurrence in over 4 years.

Olga Klepitskaya, MD, Wendy Cole, RN, MS,

Jaimie Henderson, MD, Helen Bronte-Stewart, MD, MSE

From the University of Colorado at Denver Health Sciences Center (O.K.), Aurora; and Stanford University (W.C., J.H., H.B.-S.), Stanford, $C A$.

Disclosure: Dr. Klepitskaya has received speaker honoraria from Teva Pharmaceutical Industries Ltd.; has served as a consultant for Medtronic, Inc.; performs neurophysiologic recording during $D B S$ surgeries, preoperative patient selection, and postoperative $D B S$ management, including programming; and receives research support from the Boedericker Foundation. W. Cole reports no disclosures. Dr. Henderson serves on scientific advisory boards for Intelect Medical, Inc. and Nevro Corp.; had received funding for Travel and speaker honoraria from Medtronic, Inc.; serves as a Section Editor for Neuromodulation; is listed as an inventor on patents re: Brain stimulation models, systems, devices, and methods and System and method for obtaining a volume of influence based on non-uniform tissue conductivity data; receives research support from Neurologix, Inc., the NIH, the Stanford Institute for Neuro-Innovation and Translational Neuroscience, the John A. Blume Foundation, and the Davis Phinney Foundation; and receives stock/stock options from Intelect Medical, Inc. and Nevro Corp. Dr. Bronte-Stewart serves as a consultant for Boston Scientific Corporation and receives research support from the John A. Blume Foundation and the Robert and Ruth Halperin Foundation.

Received October 7, 2010. Accepted in final form December 16, 2010. Address correspondence and reprint requests to Dr. Helen BronteStewart, Stanford University School of Medicine, 300 Pasteur Drive, Rm A-343, Stanford, CA 94305; HBS@stanford.edu 


\section{REFERENCES}

1. Takubo H, Harada T, Hashimoto T, et al. A collaborative study on the malignant syndrome in Parkinson's disease and related disorders. Parkinsonism Relat Disord 2003; 9(suppl 1):S31-S41.

2. Factor SA, Santiago A. Parkinson-hyperpyrexia syndrome in Parkinson's disease. In: Frucht S, Fahn S, eds. Movement Disorder Emergencies: Diagnosis and Treatment. New York: Humana Press; 2005:29-40.

3. Harada T, Mitsuoka K, Kumagai R, et al. Clinical features of malignant syndrome in Parkinson's disease and related neurological disorders. Parkinsonism Relat Disord 2003; 1(9 suppl):S15-S23.

4. Mizuno Y, Takubo H, Mizuta E, Kuno S. Malignant syndrome in Parkinson's disease: concept and review of the literature. Parkinsonism Relat Disord 2003;1(9 suppl):S3-S9.

5. Hashimoto T, Tokuda T, Hanyu N, Tabata K, Yanagisawa N. Withdrawal of levodopa another risk factors for malignant syndrome in Parkinson's disease. Parkinsonism Relat Disord 2003;1(9 suppl):S25-S30.
6. Ueda M, Hamamoto M, Nagayama H, et al. Susceptibility to neuroleptic malignant syndrome in Parkinson's disease. Neurology 1999;52:777-781.

7. Ikebe S, Harada T, Hashimoto T, Kanazawa I, et al. Prevention and treatment of malignant syndrome in Parkinson's disease: a consensus statement of the malignant syndrome research group. Parkinsonism Relat Disord 2003;1(9 suppl):S47-S49.

8. Gordon PF, Frucht SJ. Neuroleptic malignant syndrome in advanced Parkinson's disease. Mov Disord 2001;16:960-962.

9. Linazasoro G, Van Blercom N, Castro A, Dapena MD. Subthalamic deep brain stimulation masking possible malignant syndrome in Parkinson's disease. Neurology 2004; 63:589-590.

10. Factor S. Fatal parkinsonism-hyperpyrexia syndrome in a Parkinson's disease patient while actively treated with deep brain stimulation. Mov Disord 2007;22:148-153.

11. Kim JH, Kwon TH, Koh SB, Park JY. Parkinsonismhyperpyrexia syndrome after deep brain stimulation surgery: case report. Neurosurgery 2010;66:E1029. 


\section{Neurology}

\section{Deep Brain Stimulation in "On"-State Parkinson Hyperpyrexia \\ Olga Klepitskaya, Wendy Cole, Jaimie Henderson, et al. Neurology 2011;76;S69-S71 \\ DOI 10.1212/WNL.0b013e31820c35c7}

\section{This information is current as of February 14, 2011}

\section{Updated Information \& Services \\ Supplementary Material}

\section{References}

Subspecialty Collections

Permissions \& Licensing

Reprints including high resolution figures, can be found at: http://n.neurology.org/content/76/7_Supplement_2/S69.full

Supplementary material can be found at: http://n.neurology.org/content/supp1/2011/02/14/76.7_Supplement_2.S 69.DC1

This article cites 10 articles, 2 of which you can access for free at: http://n.neurology.org/content/76/7_Supplement_2/S69.full\#ref-list-1

This article, along with others on similar topics, appears in the following collection(s):

\section{All Movement Disorders}

http://n.neurology.org/cgi/collection/all_movement_disorders Parkinson's disease/Parkinsonism

http://n.neurology.org/cgi/collection/parkinsons_disease_parkinsonism Surgery/Stimulation

http://n.neurology.org/cgi/collection/surgery-stimulation

Tremor

http://n.neurology.org/cgi/collection/tremor

Information about reproducing this article in parts (figures,tables) or in its entirety can be found online at:

http://www.neurology.org/about/about_the_journal\#permissions

Information about ordering reprints can be found online: http://n.neurology.org/subscribers/advertise

Neurology ${ }^{\circledR}$ is the official journal of the American Academy of Neurology. Published continuously since 1951, it is now a weekly with 48 issues per year. Copyright Copyright (? 2011 by AAN Enterprises, Inc.. All rights reserved. Print ISSN: 0028-3878. Online ISSN: 1526-632X.

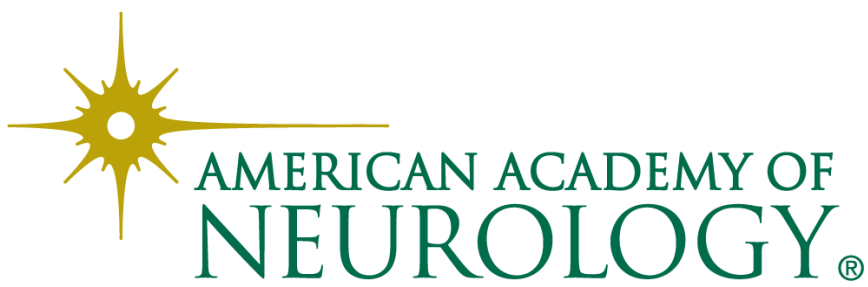

